ORIGINAL ARTICLE

\title{
Knowledge and Practice of Gynecologists about Oral Hygiene Measures during Pregnancy
}

\author{
FAREED AHMAD ${ }^{1}$, ALI ANWAAR ${ }^{2}$, MUHAMMAD SHAIRAZ SADIQ ${ }^{3}$, ALINA SAEED $^{4}$, BILAL ABDUL QAYUM MIRZA ${ }^{5}$, \\ MUHAMMAD AFZAL ${ }^{6}$ \\ ${ }^{1}$ Assistant Professor and Head of Department of Oral Medicine Institute of Dentistry CMH, Lahore \\ ${ }^{2}$ Assistant Professor, Department of Community and Preventive Dentistry, Institute of Dentistry CMH, Lahore \\ ${ }^{3}$ Associate Professor, Department of Oral Medicine, Institute of Dentistry CMH, Lahore \\ ${ }^{4}$ Demonstrator, Department of Oral Medicine, Institute of Dentistry CMH, Lahore \\ ${ }^{5}$ Professor Department of Community and Preventive Dentistry, Institute of Dentistry CMH, Lahore \\ ${ }^{6}$ Associate Professor, Department of Prosthodontics, Institute of Dentistry CMH, Lahore \\ Correspondence to: Dr. Fareed Ahmad, Email: drfareedahmad@yahoo.com, Cell: +92 3214292521
}

\begin{abstract}
Objective: To evaluate the knowledge and practice of gynecologists with regard to oral and dental health during pregnancy.

Design of the Study: It was a cross-sectional study.

Study Settings: This study was carried out at Outpatient Department of Dentistry Combined Military Hospital, Lahore from January 2019 to July 2019.

Methods \& Materials: The questionnaire was distributed among 450 gynaecologists. The evaluation tool was questionnaire. It was consisted on 23 items in which 18 questions were about the knowledge and five questions about the practice. The response of the respondents was received as yes or no. All the collected data entered in software and statistical analysis of data was done using the SPSS version 22.0. For quantitative variables mean and standard deviation were calculated. Qualitative variables were presented in the form of frequency and percentage.

Results: In our study response rate was found to be $84.4 \%$. During pregnancy related to the oral healthcare average of gynaecologist's knowledge was $12.31 \pm 2.73$ which showed that they have appropriate knowledge level. During pregnancy related to the oral healthcare measures average of gynaecologist's knowledge was $3.31 \pm$ 1.256 which exhibited that they have appropriate knowledge level of practices measures. A significant relationship between year of graduation and gynaecologist's knowledge was observed $(P=0.31)$, whereas insignificant relationship between graduation year and practice was observed $(P=0.763)$. During pregnancy related to the need of oral and dental care before \& during pregnancy gynaecologist's knowledge was $3.67 \pm 1.035$.

Conclusion: Gynecologist's knowledge about oral and dental hygiene measure during the pregnancy was appropriate. Women who are planning their pregnancy must get knowledge from dentist, obstetricians and gynecologists to reduce the rate of complications. Effect of pregnancy on oral and dental hygiene is on the one hand and inhibition from its side effects is on the other hand.

Keywords: Gynecologist, Oral Health, Pregnant women
\end{abstract}

\section{INTRODUCTION}

Oral health reflects and influences the general health of any given individual to a significant level. While it is a critical aspect of individual health, it becomes more important in the case of pregnant women whereby maternal oral health has serious implications for birth outcomes as well as infant oral health ${ }^{1}$. There have been instances cited of maternal periodontal diseases that are associated with preterm births, development of preeclampsia, and delivery of small-for-gestational age infant ${ }^{2}$.

Prior research indicates that women are exposed to two major mouth related diseases during the preconception and pregnancy periods: periodontal disease and dental caries ${ }^{3,4}$. These diseases not only impact her own oral health but also increase the risk of other diseases such as atherosclerosis, diabetes and rheumatoid arthritis, while also amplifying the risk exposure of the infant to developing severe dental caries ${ }^{4}$. Moreover, cariogenic bacteria are also typically acquired by newborns through direct salivary transmission from their mothers ${ }^{5}$. Prior

Received on 02-02-2021

Accepted on 14-06-2021 studies indicate that the prevalence rates of gingivitis during pregnancy typically range between $30 \%$ and $100 \%$ 6 . This is primarily caused by changes in hormonal levels such as estrogen and progesterone during pregnancy which ultimately can lead to inflammatory response and increased permeability of blood vessels, and even oral cavities and oral tumor 7,8 .

Educational interventions, such as dietary guidelines, etc. can particularly reduce the incidence of oral diseases amongst pregnant women, while also minimizing the risk of transmission of such diseases to the offspring ${ }^{9,10}$.

In pregnant women lack of appropriate knowledge worried them about care or treatment of themselves and health of their fetal. So as their doctor gynecologist's role is very important as they have to change their mind which is strongly associated with their knowledge which specialist physician give to their patients. That's why gynecologist must have appropriate knowledge of dental and oral ups and downs occurred in pregnancy. So this study is undertaken to check the knowledge and practice of gynecologists about dental and oral measures during pregnancy. 


\section{METHODS AND MATERIALS}

It was cross sectional questionnaire-based survey. Approval was taken from the Ethical Review Board, $\mathrm{CMH}$ Lahore (Case\#501/ERC/CMH/LMC) and from the respective post graduate trainees and consultations and Specialists. The departments of Gynecology and Obstetrics in four public and private hospitals were targeted in Lahore city. (Fatima Memorial Hospital, Ghurki Trust Teaching Hospital, Sir Ganga Ram Hospital and Combined Military Hospital $(\mathrm{CMH})$ Lahore The questionnaire was distributed among 450 gynecologists.

About knowledge the questionnaire was consisted on 6 questions and 6 questions was related the practices then questions were related to oral hygiene and dental care measures during the pregnancy. The response of the respondents was received as yes or no. After answers of the all question items the reliability was calculated by Kappa coefficient for all the question items. Among twenty five questions about the knowledge 6 questions were excluded and among those 6 questions which were related to the practice 1 question was excluded. Lastly a questionnaire was prepared which was containing twenty three questions in which eighteen questions about the knowledge (Q; 1 to 19) and 5 questions were about the practice (Q; 19 to 23). Then the proforma was sub-divided into 6 portions. First 5 portions were about the knowledge of the respondents and the end section was about the practice. Yes/No answers of the respondents were taken out and described as the level of gynecologist and practice of them.

All the collected data entered in software and statistical analysis of data was done using the SPSS version 22.0. For quantitative variables mean and standard deviation were calculated. Qualitative variables were presented in the form of frequency and percent (\%). To evaluate the relationship between practice and knowledge scores with graduation year and age spearman correlation coefficient was applied. A p-value $\leq 0.05$ was considered as statistically significant.

\section{RESULTS}

In present study response rate was found to be $84.4 \%$. From the 450 gynecologists, Total 380 respondents complete the questionnaire among the 450 gynecologist which were taken as a sample size. In final analysis of data total 380 respondents were include with average age $45.69 \%$. During pregnancy related to the oral healthcare average of gynecologist's knowledge was 12.31 \pm 2.73 which showed that they have appropriate knowledge level. During pregnancy related to the oral healthcare measures average of gynecologist's knowledge was $3.31 \pm 1.256$ which exhibited that they have appropriate knowledge level of practices measures.

Table-1 showed the demographic details of the respondents. A significant relationship between year of graduation and gynecologist's knowledge was observed ( $P$ $=0.31$ ), whereas insignificant relationship between graduation year and practice was observed $(P=0.763)$. During pregnancy there was insignificant relationship was observed about the oral health care measures between age $(p=0.87)$ and practice \& knowledge $(p=0.8)$ of gynecologists.

During pregnancy related to the requirement of oral and dental hygiene gynecologist's knowledge was $3.67 \pm$ 1.035 .

Table 1: Sociodemographic the study respondents

\begin{tabular}{|l|l|}
\hline \multicolumn{2}{|l|}{ Sociodemographic characteristics } \\
\hline Demographics & $\mathrm{n}(\%)$ \\
\hline Age (years), mean \pm SD & $44.76 \pm 9.342$ \\
\hline Occupation & $103(26.3 \%)$ \\
\hline$\bullet \quad$ Academic & $176(48.1 \%)$ \\
$\bullet \quad$ Nonacademic & $95(23.1 \%)$ \\
\hline$\quad$ Academic/nonacademic \\
\hline Work experience & $34(8.1 \%)$ \\
\hline$-\quad 1-5$ years & $57(13.3 \%)$ \\
$\bullet-10$ & $57(14.9 \%)$ \\
$\bullet \quad 11-15$ & $150(40.6 \%)$ \\
\hline No response & $83(22.3 \%)$ \\
\hline
\end{tabular}

Table 2: Gynecologists' oral health knowledge during pregnancy

\begin{tabular}{|c|c|c|c|c|}
\hline \multirow{6}{*}{\begin{tabular}{|l} 
Knowledge \\
Need to oral \\
and dental care \\
before and during \\
pregnancy
\end{tabular}} & Item number & Yes (\%) & No (\%) & \multirow{6}{*}{$\frac{\text { Mean } \pm \text { SD }}{3.67 \pm 1.035}$} \\
\hline & 1. Patient who is planning to get pregnant should be referred to the dentist before pregnancy & $324(85.26)$ & $53(13.96)$ & \\
\hline & 2. At the beginning of pregnancy, there is a need fordental and mouth examination by a dentist & $318(83.68)$ & $51(13.43)$ & \\
\hline & 3. Good control of oral hygiene during pregnancy is essential for pregnant women & $322(84.73)$ & $48(12.64)$ & \\
\hline & $\begin{array}{l}\text { 4. When you find any suspicious clinical dental symptoms, the patient should be referred to the } \\
\text { dentist }\end{array}$ & $293(77.10)$ & $77(20.27)$ & \\
\hline & 5. Pregnant women should be advised to delay dental treatments until delivery & $137(36.05)$ & $232(61.06)$ & \\
\hline \multirow{2}{*}{$\begin{array}{l}\text { Oral and dental } \\
\text { hygiene during } \\
\text { pregnancy }\end{array}$} & $\begin{array}{l}\text { 6. Health-care practices (brushing teeth or mouthwashing) are necessary after morning nausea and } \\
\text { vomiting }\end{array}$ & $313(82.38)$ & $61(16.05)$ & \multirow[t]{2}{*}{$1.61 \pm 0.596$} \\
\hline & 7. Scaling and plaque control before pregnancy reduces gingivitis during pregnancy? & $297(78.15)$ & $74(19.49)$ & \\
\hline \multirow{3}{*}{$\begin{array}{l}\text { Effects of } \\
\text { pregnancy on oral } \\
\text { and dental hygiene }\end{array}$} & 8. Pregnancy can cause gingivitis & $279(73.43)$ & $88(23.15)$ & \multirow[t]{3}{*}{$2.11 \pm 0.941$} \\
\hline & 9. Pregnancy can cause gingival bleeding & $271(71.32)$ & $96(25.26)$ & \\
\hline & 10. Pregnancy can increase the tooth decay & $250(65.78)$ & $119(31.33)$ & \\
\hline \multirow{3}{*}{$\begin{array}{l}\text { Effects of oral } \\
\text { diseases on } \\
\text { pregnancy }\end{array}$} & 11. Periodontal diseases can cause preterm delivery & $256(67.36)$ & $98(25.78)$ & \multirow[t]{3}{*}{$2.07 \pm 1.044$} \\
\hline & 12. Periodontal diseases can cause low birth weight & $280(73.68)$ & $82(21.57)$ & \\
\hline & 13. Oral diseases can cause increased blood pressure during pregnancy & $249(65.52)$ & $111(29.22)$ & \\
\hline \multirow{5}{*}{\begin{tabular}{|l} 
Dental procedures \\
during pregnancy
\end{tabular}} & 14. Taking dental radiography in the second trimester with a lead apron is permitted & $257(67.63)$ & $110(28.94)$ & \multirow[t]{5}{*}{$2.90 \pm 1.152$} \\
\hline & 15. In the second trimester of pregnancy, dental procedures such as scaling are permitted & $247(65)$ & $123(32.37)$ & \\
\hline & 16. In the second trimester of pregnancy, teeth extraction is permitted & $239(62.89)$ & $124(32.63)$ & \\
\hline & 17. The use of dental anesthetic containing lidocaine and epinephrine is permitted during pregnancy & $210(55.26)$ & $159(41.85)$ & \\
\hline & 18. In the second trimester, we can do all dental procedure & $150(39.47)$ & $216(56.84)$ & \\
\hline Total & 18 & & & $12.35 \pm 2.737$ \\
\hline
\end{tabular}


Table 3: During pregnancy oral health practice of Gynecologists

\begin{tabular}{|c|c|c|c|c|}
\hline Practice & Item No & Yes (\%) & No (\%) & Mean \pm SD \\
\hline Performing health & 19. Recommend fluoride therapy to pregnant women & $237(62.36)$ & $130(34.22)$ & $3.31 \pm 1.256$ \\
\hline cares and oral and & 20. Recommend routine oral examinations to pregnant patients & $276(72.63)$ & $88(23.15)$ & \\
\hline dental hygiene & 21. I refer patients to the dentist for dental check at the beginning of pregnancy & $267(70.27)$ & $96(25.26)$ & \\
\hline during pregnancy & 22. I look for early symptoms of inflammation in the patient's mouth in their visits & $236(62.10)$ & $124(32.63)$ & \\
\hline
\end{tabular}

\section{DISCUSSION}

Related to the dental and oral health care measures out of 18 the mean average score during pregnancy was $12.31 \pm$ 2.72 , on the other hand out of five mean average practice score which observed was $3.37 \pm 1.26$ which showed that gynecologists have appropriate level of knowledge. In present study gynecologist mean age was in line with mean age of pregnant women included in the study conducted by Cohen et al. \& Wilder et al. ${ }^{13,14}$

Most of the study participants were belong to nonacademic occupations. In a study by Cohen et al. in his study reported that, $47.9 \%$ gynecologists were doing their private practice, $16.8 \%$ in hospital as well as in clinics and $35.3 \%$ working in only hospital. ${ }^{14}$ Our study results were also similar with Shah et al. who noted insignificant relationship between gynecologists knowledge and their ages. ${ }^{15}$

During pregnancy about the oral and dental hygiene measures $>80 \%$ participants assumed that scaling and plaque control decrease the "gingivitis" and $75 \%$ respondents believed that pregnancy can cause bleeding and gingivitis. Our these finding are in line with results of Shenoy's et al. who found it to be $77 \% .^{16}$

During pregnancy in dental procedures out of five the mean average knowledge was $2.89 \pm 1.15$. Almost $60 \%$ respondents were know that tooth extraction, scaling, X-ray of dental procedures are allowed during $2^{\text {nd }}$ trimester and not harmful, $56.9 \%$ were sentient that adrenaline and lidocaine (dental analgesics) are allowed during pregnancy while only $41 \%$ respondents respond that dental surgeries could not be performed during the $2^{\text {nd }}$ trimester of pregnancy. A study showed gynecologists response was 97.4\% regarding dental procedures are promising during pregnancy conducted by Cohen et al. ${ }^{14}$

Golkari et al. stated that gynecologists asked their $80 \%$ patients to get checkup of oral health in pregnancy. In the same research, $41.7 \%$ gynecologists indicated that in their $1^{\text {st }}$ visit they do the checkup of oral health condition of pregnant women. ${ }^{19}$

\section{CONCLUSION}

Gynecologist's knowledge about oral and dental hygiene measure during the pregnancy was appropriate. Women who are planning their pregnancy must get knowledge from dentist, obstetricians and gynecologists to reduce the rate of complications. Effect of pregnancy on oral and dental hygiene is on the one hand and inhibition from its side effects is on the other hand.

\section{REFERENCES}

1. lida $\mathrm{H}$. Oral Health Interventions During Pregnancy. Dent Clin North Am. 2017 Jul;61(3):467-481.

2. Al-Habashneh R, Aljundi SH, Alwaeli HA. Survey of medical doctors' attitudes and knowledge of the association between oral health and pregnancy outcomes. Int J Dent Hyg. 2008 Aug;6(3):214-20.
3. Boggess KA, Edelstein BL. Oral health in women during preconception and pregnancy: implications for birth outcomes and infant oral health. Matern Child Health J. 2006 Sep;10(5 Suppl): S169-74.

4. Morgan MA, Crall J, Goldenberg RL, Schulkin J. Oral health during pregnancy. J Matern Fetal Neonatal Med. 2009 Sep;22(9):733-9.

5. Thomas NJ, Middleton PF, Crowther CA. Oral and dental health care practices in pregnant women in Australia: a postnatal survey. BMC Pregnancy Childbirth. 2008 Apr 21; 8:13.

6. Rakchanok N, Amporn D, Yoshida Y, Harun-Or-Rashid M, Sakamoto J. Dental caries and gingivitis among pregnant and non-pregnant women in Chiang Mai, Thailand. Nagoya J Med Sci. 2010 Feb;72(1-2):43-50.

7. Monalisa, R. (2015) Oral Health in Pregnancy. Research Journal of Pharmacy and Technology, 8 (8), pp 1129-1131.

8. George A, Dahlen HG, Reath J, Ajwani S, Bhole S, Korda A, Chok HN, Miranda C, Villarosa A, Johnson M. What do antenatal care providers understand and do about oral health care during pregnancy: a cross-sectional survey in New South Wales, Australia. BMC Pregnancy Childbirth. 2016 Dec 1;16(1):382.

9. Suri V, Rao NC, Aggarwal N. A study of obstetricians' knowledge, attitudes and practices in oral health and pregnancy. Educ Health (Abingdon). 2014 Jan-Apr;27(1):51-4.

10. Ayaz A, Mureed S, Abbasi ZA, Ayaz N, Farooq N, S. Perceptions of Antenatal Care providers about Oral Health of Pregnant Women at the Hospitals of Karachi. PJPH [Internet]. 2019 Dec 9 [cited 2020 Dec 3]; 9(2):64-8.

11. Sattar FA, Khan AH. Prenatal Oral health care and dental service utilization by pregnant women: A survey in four maternity centres of Gulshan Town, district east, Karachi. J Pak Dent Assoc 2020;29(2):60-65.

12. Morgan MA, Crall J, Goldenberg RL, Schulkin J. Oral health during pregnancy. $\mathrm{J}$ Matern Fetal Neonatal Med. 2009;22(9):733-9.

13. Wilder $R$, Robinson $\mathrm{C}$, Jared $\mathrm{HL}$, Lieff $\mathrm{S}$, Boggess $\mathrm{K}$. Obstetricians' knowledge and practice behaviors concerning periodontal health and preterm delivery and low birth weight. $J$ Dent Hyg 2007;81:81.

14. Cohen L, Schaeffer M, Davideau JL, Tenenbaum H, Huck O. Obstetric knowledge, attitude, and behavior concerning periodontal diseases and treatment needs in pregnancy: influencing factors in France. J Periodontol 2015;86:398-405.

15. Shah HG, Ajithkrishnan C, Sodani V, Chaudhary NJ. Knowledge, attitude and practices among gynecologists regarding oral health of expectant mothers of Vadodara city, Gujarat. Int J Health Sci (Qassim) 2013;7:136-40.

16. Shenoy RP, Nayak DG, Sequeira PS. Periodontal disease as a risk factor in pre-term low birth weight - An assessment of gynecologists' knowledge: A pilot study. Indian J Dent Res 2009;20:13-6.

17. Patil S, Thakur R, KM, Paul ST, Gadicherla P. Oral health coalition: Knowledge, attitude, practice behaviours among gynaecologists and dental practitioners. J Int Oral Health 2013;5:8-15.

18. Rocha JS, Arima L, Chibinski AC, Werneck RI, Moysés SJ, Baldani $\mathrm{MH}$, et al. Barriers and facilitators to dental care during pregnancy: A systematic review and meta-synthesis of qualitative studies. Cad Saude Publica 2018;34:e00130817.

19. Golkari A, Khosropanah H, Saadati F. Evaluation of knowledge and practice behaviours of a group of Iranian obstetricians, general practitioners, and midwives, regarding periodontal disease and its effect on the pregnancy outcome. J Public Health Res 2013;2:e15. 